\title{
NERVOUS AND HORMONAL CONTROL OF ADIPOSE TISSUE
}

\author{
T. M. Chalmers, M.D., M.R.C.P. \\ Consultant Physician, \\ Addenbrooke's Hospital, Cambridge.
}

UNTIL quite recently adipose tissue was regarded as metabolically inert, its function limited to insulation and support and the passive storage of fat. Even after the classic work of Schoenheimer and Rittenberg (1937) had shown that adipose tissue participated in the continuous dynamic processes of the body, its role in energy metabolism continued to be accounted of far less importance than that of the liver. The modern era of revolutionary development in adipose tissue studies may be said to have begun with the review by Wertheimer and Shapiro in 1948 in which they concluded that adipose tissue was a specialised tissue supplied by a relatively dense capillary network and innervated by sympathetic nerve fibres, that deposition and mobilisation of fat were active processes involving the metabolism of the tissue, that synthesis of new fatty acids from carbohydrates proceeded continuously and that these metabolic activities were regulated by nervous and endocrine factors.

In the general survey which follows no attempt will be made to cite all the original publications on which it is based. Reviews published within the last four years include those of Wertheimer and Shafrir (1960), Vaughan (1961), Jeanrenaud (1961), Winegrad (1962), Kinsell (1962), Steinberg (1963) and Renold and Cahill (1964).

\section{The Metabolism of Adipose Tissue}

Glucose metabolism. Glucose utilisation in adipose tissue as in muscle is regulated by the supply of intracellular glucose-6-phospate. This, in turn, depends on the transport of glucose across the cell membrane and its phosphorylation in the presence of hexokinase and ATP. Phosphorylation of glucose is unlikely to be the rate-limiting step because adipose tissue hexokinase is saturated at extremely low concentrations of glucose, and it is therefore probable that the control of glucose metabolism is exerted at the level of glucose transport across the cell membrane. The problem of transport is complicated in adipose tissue by the existence of an active pinocytosis (Barrnett and Ball, 1960), whose metabolic function is uncertain.
Glucose-6-phosphate is metabolised both by glycolysis and via the pentose phosphate shunt. The "shunt" is particularly active in adiposes tissue and was, until recently, believed to bes the major source of the reduced coenzymesnecessary for the synthesis of fatty acids fromw glucose. According to Flatt and Ball (1963); however, only about half the coenzymes? required are produced in the pentose cycle, the remainder being furnished during the conversion of triose phosphate to acetyl. CoA. This process indeed generates reducedf coenzymes in far greater amounts than are needed to complete the reductiveo synthesis of fatty acids and this surplus must be oxidised if fatty acid synthesis is to proceed $?$

Glycogen storage and mobilisation are of relatively little importance in this tissue. Most of the carbon from labelled glucose is found in carbon dioxide, glyceride-glycerol and fa $p$ acids. $\alpha$-glycerophosphate, the precursor glyceride-glycerol, is formed by reduction dihydroxyacetone phosphate in the presence of NADH. It is important to note that adiposen tissue cannot phosphorylate the glycerol madeo available by triglyceride breakdown and the rate of esterification of free fatty acids is thuso regulated by the level of glucose metabolism in the tissue. Recent studies in $\operatorname{man} \frac{}{0}$ however, suggest that glycerol may be con served under some conditions (Carlson and Orö, 1963; Shafrir and Gorin, 1963; HagenMoorhouse and Steinberg, 1963).

Synthesis and hydrolysis of triglycerides. Glyceride synthesis requires the presence of both glycerol and fatty acids in an "activated" state and depends on the continuous production of energy in the form of ATP. Hydrolysis of triglycerides in adipose tissue is observed at two quite distinct points. Thus the incorpor ation of plasma glycerides into adipose tissue stores is preceded by their hydrolysis under tho influence of lipoprotein lipase: this reaction is believed to occur at the cell surface. On the other hand, the hydrolysis of stored triglycerides is catalysed by a different lipase system, located within the cell and activated 
by the presence in the tissue of hormones or lipolytic substances.

Mobilisation of fatty acids. Both synthesis and hydrolysis of stored triglycerides proceed continuously. The resting fat cell thus contains a pool of free fatty acids in dynamic equilibrium with stored triglycerides. Net accumulation of free fatty acids leading to their nelease into the circulation will result from either a decrease in the rate of synthesis or an increase in the rate of hydrolysis of triglycerides. Conversely, net deposition of triglycerides and suppression of fatty acid release will occur if the rate of synthesis is increased or the rate of breakdown is decreased.

Glycerol production. Considerable amounts of glycerol are produced in adipose tissue by hydrolysis of circulating as well as stored triglycerides. Studies of plasma glycerol concentration and turnover rate in the rabbit indicate that in the normal animal about 10 per cent of the calories used may be derived from glycerol. In the starved animal the value may be consirlerably greater (Hagen, 1963).

\section{Effects of Hormones in Adipose Tissue}

Most of the hormonal effects in adipose tissue can be explained on the basis of two principal sites of control. They are (1) the transformation of extracellular glucose into intracellular glucose-6-phosphate, and (2) the activity of the intracellular lipase system responsible for the breakdown of stored triglycerides.

Insulin. Since the presence of insulin augments all phases of glucose metabolism its primary effect is thought to be at the level of transport of glucose across the cell membrane, or, less probably, on its phosphorylation. Synthesis of glyoogen, glycolysis, oxidation in the pentose cycle and synthesis of fatty acids are all increased: the production of increased amounts of $\alpha$-glycerophosphate promotes storage of fatty acids as triglycerides and inhibits their release into the circulation. Similar effects are produced by increasing the concentration of glucose to which the tissue is exposed, provided some insulin is present. Lack of insulin inhibits glucose uptake and lipogenesis, and favours the release of free fatty acids into the circulation. Despite the acceleration of glucose metabolism by insulin and glucose, the oxidation of acetyl-CoA in the Krebs cycle is not increased and may actually be reduced (Flatt and Ball, 1963). The partial shutdown of the cycle may be a compensatory mechanism permitting re-oxidation of the surplus reduced coenzymes produced during the process of converting glucose into fat.

The metabolic effects of insulin in adipose tissue are associated with remarkable ultrastructural changes (Barrnett and Ball, 1960). When rat adipose tissue which has been incubated in vitro in the presence of insulin and glucose is examined with the electron microscope the cytoplasm is found to have changed from a granular to an agranular state and to have become filled with membrane-bound vesicles. The mitochondria have become elongated and pleomorphic and free lipid inclusions have appeared in the cytoplasm. The plasma membrane is seen to be indented at many sites to form finger-like invaginations and beneath it lie numerous tiny vesicles suggesting that pinocytosis is occurring.

While insulin is certainly the most important agent regulating glucose metabolism and lipogenesis it must be noted that similar effects have been produced under certain experimental conditions with prolactin and with oxytocin.

Lipolytic substances. A large number of substances has been shown to be capable of releasing fatty acids from adipose tissue. They include (1) catecholamines-adrenaline, noradrenaline and certain analogues; (2) glucagon; (3) FMS - a fat-mobilising substance found in fasting urine (Chalmers, Pawan and Kekwick, 1960; Chalmers, 1964); (4) pituitary substances -growth hormone, ATCH, TSH, FSH, $\alpha$ and $\beta$-MSH and arginine vasopressin: and a number of lipolytic peptides isolated from pituitaries, namely "fraction H" (Rudman, Reid, Seidman di Girolamo and Bern, 1961). "peptide I" (Friesen, Barrett and Astwood, 1962) and "lipotropin" ( $\mathrm{Li}, 1964)$. The structure of peptide I has been partially elucidated and it is shown to be a derivative of pig $\beta$-MSH (Hofmann and Katsoyannis, 1963). Lipotropin has 59 amino acids and a molecular weight of 6,600. A number of synthetic peptides related to corticotropin also have adipokinetic activity (Raben, Landolt, Smith, Hofmann and Yajima, 1961).

These agents liberate fatty acids from adipose tissue by directly augmenting the lipolytic reaction. Rizack (1961) succeeded in isolating the intracellular lipolytic system in cell-free preparations and showed that its activity was enhanced by previous treatment with adrenaline as well as by starvation. Activity lost as a result of incubation could be restored by addition of adrenaline and ATP. Similar effects 
have been obtained with ACTH, TSH and glucagon.

Consideration of the diversity of molecular structures capable of stimulating the lipolytic reaction led to the suggestion that peptide hormones such as ACTH might act indirectly by releasing or activating catecholamine stored in the tissue (Paoletti, Smith, Maickel and Brodie, 1961). However, contrary to earlier belief, the response to ACTH is not abolished by depletion of catecholamine stores (Edmonson and Goodman, 1962; Ho and Meng, 1964). Blocking the response to adrenaline with DCI (dichloro-isoproterenol) does not inhibit the lipolytic effect of ACTH in vitro (Goldiner and Chalmers, unpublished). And neither ganglionic nor adrenergic blockade interferes with the mobilisation of free fatty acids by growth hormone in monkeys. Moreover the adipose tissue of rabbits and guineapigs is highly sensitive to certain pituitary peptides but quite insensitive to catecholamines.

Another possible mode of action common to both catecholamines and peptide hormones is through adenosine- $3^{\prime}, 5^{\prime}$-phospate or $3^{\prime}$, $5^{\prime}$-AMP. This substance is believed to be concerned in the action of hormones in many tissues, for example in glycogen breakdown by adrenaline and glucagon in liver and in steroidogenesis by ACTH in adrenal cortex (Sutherland, 1962). Accumulation of $3^{\prime}, 5^{\prime}$ AMP in a particulate fraction of adipose tissue is enhanced by adrenaline, and $3^{\prime}$, 5'-AMP itself activates the adrenaline-sensitive lipolytic system (Rizack, 1964). Addition of $3^{\prime}, 5^{\prime}$-AMP to the medium in which adipose tissue is incubated causes, however, none of the changes produced by adrenaline under similar conditions. This does not. of course, exclude the possibility that the nucleotide formed within the tissue plays a role in the effects of adrenaline and certain other hormones (Vaughan, 1961).

There are considerable species differences in the responsiveness of adipose tissue to lipolytic hormones. Rabbit and guinea-pig adipose tissues are highly responsive to nearly all the pituitary peptides listed but unresponsive to catecholamines and FMS. Rat, dog and probably mouse and hamster adipose tissues respond only to certain pituitary substances but are highly sensitive to FMS and catecholamines. Pig adipose tissue has so far proved unresponsive to all substances tested (Rudman, Brown and Makin, 1963). Human adipose tissue probably behaves like rat and dog: thus it is known to respond to catecholamines, FMS and growth hormones, but not to peptide I or fraction $\mathrm{H}$. Variations in sensitivity among different species may be due to inactivating enzymes (Rudman, Malkin, Brown, Garcie and Abell, 1964). Rat adipose tissue contains an enzyme capable of inactivating ACTH and: rabbit adipose tissue inactivates $\alpha$-MSH however, in both cases a lipolytic response occurs.

Besides their primary effect on the lipolyti商 mechanism these hormones produce charactes istic changes in glucose metabolism believed to be mediated by a rise in the intracellular concentration of fatty acids, and consisting in (1) an increase in glucose uptake and adt increase in the incorporation of gluoose carbo: into glyceride-glycerol (2) a relative decrease in the metabolism of glucose over the pentose pathway, and (3) an increase in the oxidatio of glucose by the Krebs cycle (Lebøuf and Cahill, 1961). In addition, in the presence of insulin there is an even greater increase i⿺ glucose incorporation into glyceride-glycerdf and the insulin effects on glycogen and fatt $\bar{y}$ acid synthesis are inhibited. The increased incorporation of glucose into glyceride-glycer/ is interpreted as evidence of increased $r \xi^{2}$ esterification of fatty acids. A large and sus:tained increase in oxygen consumpogos accompanies this rapid hydrolysis and gres synthesis of triglyceride within the tissue (Baty and Jungas, 1961) and it is possible that hea generated in this way may at times contribute to the maintenance of body temperature. Thu Dawkins and Hull (1963) have shown that 道 the new-born rabbit exposed to cold the tem perature in brown fat may exceed the colonie temperature by as much as $2^{\circ} \mathrm{C}$.

\section{Physiological Role of Hormones}

Studies in intact animals and clinical and experimental observations in man confirm thät insulin and glucose are the major regulators $\bar{f}$. fat accumulation. In obese subjects, both diag betic and non-diabetic, excessive insulin pre duction has been repeatedly demonstrated (Rabinowitz and Zierler, 1962; Hales an Randle, 1963; Grodsky, Karam, Pavlato and Forsham, 1963). Administration of insulin or glucose also promptly reduces the $\mathrm{V}$-A difference of free fatty acids (FFA) in pef fused adipose tissue and lowers plasma FFA levels in intact animals, including man. This immediate response is presumably due to increased esterification of FFA in adipose tissue.

Although there is still much uncertainty about the physiological role of lipolytic hog mones, it is becoming clear that the activit罗 
of the sympathetic nervous system is a major factor in determining the levels of both FFA and other lipid fractions in plasma. Electrical stimulation of nerves supplying adipose tissue increases the output of FFA, presumably through release of noradrenaline at the nerveendings; whereas denervation of adipose tissue reduces its ability to mobilise its lipid during fasting. Ganglionic blockade reduces plasma FFA levels in the dog. Infusion of adrenaline or noradrenaline in man produces a prompt elevation of plasma FFA: this effect can be abolished by pronethalol. Similarly, the sympathetic discharge associated with emotional stress can markedly raise plasma FFA levels; the relative contributions of sympathetic nerves and adrenal medulla to this response are not known. Nestel (1964) has shown that fasting plasma triglyceride levels may be correlated with the increment in plasma FFA following noradrenaline infusion in both normal subjects and those with coronary heart disease.

Thyroid and adrenocortical hormones have been shown to have important indirect effects on fat mobilisation. The response to adrenaline is markedly impaired both in vivo and in vitro in adrenalectomised animals and can be restored by pre-treatment with cortisone. The permissive effect of cortisone is obtained with doses that do not by themselves alter plasma FFA levels: a direct lipolytic effect may be obtained in vitro with rather high concentrations. A similar permissive effect of triiodothyronine has been shown in hypophysectomised monkeys: in this case glucocorticoids alone were without effect on the adrenaline response. (Harlan, Laszlo, Bogdonoff and Estes, 1963, a, b) have shown that the response of plasma FFA to infusions of adrenaline and noradrenaline is increased in hyperthyroidism and decreased in hypothyroidism. Hyperthyroid patients tend to have elevated plasma FFA levels.

The extent to which pituitary hormones are more directly involved in fat mobilisation is less clear and may well vary in different species. In man there are strong grounds for assigning an important role to growth hormone. The administration of human growth hormone (HGH) causes a large increase in plasma FFA, the response being relatively slow and longlasting in comparison with that elicited by catecholamines. Recent studies of HGH secretion (Jansz, Doorenbos and Reitsma, 1963; Roth, Glick, Yalow and Berson, 1963) indicate that fasting and hypoglycæmia are associated with high plasma HGH levels and that the adminis- tration of glucose causes an abrupt fall in plasma HGH levels. HGH concentration in plasma also rises when the uptake of glucose is blocked by 2-deoxyglucose and after muscular exercise. Hunter and Greenwood (1964) found the half-life of endogenous HGH to be about 20 mins. These studies establish the existence in man of a mechanism for controlling the secretion of growth hormone sensitive to the availability of intracellular glucose and capable of fairly rapid responses.

There is still considerable doubt about the precise mode of action of growth hormone in adipose tissue. In vitro, concentrations of the order of $100 \mu \mathrm{g} / \mathrm{ml}$. are required to obtain a lipolytic response, whereas ACTH is effective at $0.01 \mu \mathrm{g} / \mathrm{ml}$. or even less. Vaughan and Steinberg (1963) re-investigated this problem and conoluded that any lipolytic effect of growth hormone preparations in vitro could be accounted for by traces of TSH. The lipolytic effect of growth hormone in vivo may therefore be due to the production of another substance capable of acting directly in adipose tissue. Such an agent could be formed from growth hormone itself by the action of a proteolytic enzyme; or it might be released from a target organ. Mechanisms involving glucagon release or interference with the action of insulin appear to be ruled out by the well-o known ketogenic effect of growth hormone in the depanoreatised dog.

Chalmers and others (1960) have reported that during fasting or restriction of carbohydrate intake the urine of man and certain other mammalian species contains a potent fat-mobilising substance (FMS) of low molecular weight. The pituitary or adjacent hypothalamus is necessary for the production of this material; but it differs from known pituitary adipokinetic substances including fraction $\mathrm{H}$, peptide I and lipotropin. The active principle has not yet been obtained in pure form and its chemical nature is unknown. It has not been detected in the urine of hypophysectomised subjects after administration of HGH, but appears to be produced in excess by some patients with acromegaly (Chalmers, 1964). Its relationship to growth hormone will therefore require further elucidation. FFAreleasing activity has been reported in serum from fasting normal subjects and untreated diabetics (Recant, Alp, Koch and Eggeman, 1963). The active substance is non-dialysable but it may prove to be FMS in bound form.

Madison, Mebane, Unger and Lochner (1964) have recently provided evidence for a stimulatory feedback of ketones on pancreatic 
beta cells. The infusion of ketones into normal dogs produces effects resembling those of a slow infusion of insulin. These effects are not seen in depancreatised dogs. Both intravenous and direct pancreatic infusion of ketone bodies cause an increased secretion of insulin into the pancreatic vein. The effect of this moohanism in prolonged starvation would be to modulate the release of FFA from adipose tissue and to regulate the rate of ketone production by the liver, and thereby to prevent the development of progressive ketoacidosis by establishing a new steady state.

\section{Conclusion}

Insulin and glucose have a threefold effect on adipose tissue metabolism. Firstly, they control the rate of lipogenesis: secondly, the influence FFA-release through their effect on re-esterification: and lastly, by thei action on cerebral metabolism they control the secretion of growth hormone and help to regulate sympathetic nervous activity? It is likely that the sympatho-medullary sy를 tem functions mainly as a rapid and shore acting fat-mobilising mechanism, while tho pituitary provides for a slower and more susa tained response which may be modulated dut ing prolonged starvation by a ketone insulin feedback. The role of glucagon and of pituitary lipolytic substances other tha $\overrightarrow{\vec{m}_{0}}$ growth hormone is at present uncertain Important indirect effects on fat mobilisation are exerted by the thyroid and adrenal cortex.

\section{REFERENCES}

BALl, E. G., and JungaS, R. L. (1961). On the Action of Hormones which Accelerate the Rate of Oxygeat Consumption and Fatty Acid Release in Adipose Tissue in vitro. Proc. nat. Acad. Sci. (Wash.), 47, 932. BARRNETT, R. J., and BALL, E. G. (1960). Metabolic and Ultrastructural Changes Induced in Adipose Tissů by Insulin. J. biophys. biochem. Cytol., 8, 83.

CARLSON, L. A. and Orö L. (1963). Studies on the Relationship between the Concentrations of Plasma Fres Fatty Acids and Glycerol in vivo. Metabolism, 12, 132.

Chalmers, T. M. (1964). Lipid-mobilising Activity during fasting. See Renold and Cahill (1964).

Chalmers, T. M., Pawan, G. L. S., and KeKwICK, A. (1960). Fat Mobilising and Ketogenic Activity of Urine Extracts: Relation to Corticotrophin and Growth Hormone. Lancet, ii, 6.

Dawkins, M. J. R., and Hull, D. (1963). Brown Fat and the Response of the New-born Rabbit to Co. J. Physiol, 169, $101 \mathrm{P}$.

Edmonson, J. H., and Goodman, W. S. (1962). Effect of Reserpine on Fatty Acid Mobilisation. Proc. Side
exp. Biol. (N.Y.), 110, 761.

FlatT, J. P., and BALL, E. G. (1963). The Role of Reduced Coenzymes and Oxygen in the Control of Fatty Acid Synthesis in Adipose Tissue. In 'The Control of Lipid Metabolism', p. 75, Ed. J. K. Grant. Londo and New York: Academic Press.

Friesen, H., Barrett, J., and Astwood, E. B. (1962). Metabolic Effects of Two Peptides from the Anterio鱼 Pituitary Gland. Endocrinology, 70, 579.

Grodsky, G. M., Karam, J. H., Pavlatos, F. C. H., and Forsham, P. F. (1963). Reduction by Phenformi $\overrightarrow{\vec{\nabla}}$ of Excessive Insulin Levels after Glucose Loading in Obese and Diabetic Subjects. Metabolism, $12,278$. HAGEN, J. H. (1963). The Rate of Turnover of Glycerol in Blood. In 'The Control of Lipid Metabolism', p?
159, Ed. J. K. Grant. London and New York: Academic Press.

Hagen, J. H., Moorhouse, J. A., and Steinberg, J. (1963). Effect of Insulin on Plasma Glycerol in Mani. Metabolism, 12, 346.

Hales, C. N., and Randle, P. J. (1963). Effects of Low-carbohydrate Diet and Diabetes Mellitus on Plasma Concentrations of Glucose, Non-esterified Fatty Acid, and Insulin during Oral Glucose-tolerance tests? Lancet, i, 790.

Harlan, W. R., Laszlo, J., Bogdonoff, M. D., and Estes, E. H., Jr. (1963a). Alterations in Free Fatt官 Acid Metabolism in Endocrine Disorders. Part I, Effect of thyroid hormone. J. clin. Endocr. 23, 33. (1963, b). Alterations in Free Fatty Acid Metabolism in Endocrine Disorders. Part $\mathbf{\Pi}$, Sequential Studies
and the Effect of 2-Deoxy-d-glucose. Ibid, 23, 41. Ho, R. J., and MENG, H. C. (1964). The Extracortical Aotion of ACTH on the Elevation of Plasma

HofFman, K., and KaTSOYANNIS, P. G. (1963). Synthesis and Function of Peptides of Biological Interest. In "The Proteins", Second Ed., Vol. 1, Ed. H. Neurath. New York and London: Academic Press. ज़ HunTER, W. M., and GREENwOOD, F. C. (1964). Studies on the Secretion of Human-Pituitary-Growth
Hormone. Brit. med. J., i, 804. JANSZ, A., DoorenBOS, H., and ReITSMA, W. D. (1963). Effect of Food Intake on Growth Hormone LevelN
Lancet, i, 250.

JeanRenaud, B. (1961). Dynamic Aspects of Adipose Tissue Metabolism. Metabolism, 10, 535.

Kinsell, L. W. (1962) Ed. "Adipose Tissue as an Organ". Springfield, Illinois: Charles C. Thomas. 236
Leberuf B., and CAHILL, G. F., Jr. (1961). Studies on Rat Adipose Tissue in vitro. J. biol. Chem., 236
41 . C1. H. (1964). Lipotropin, a New Active Peptide from Pituitary Glands. Nature, 201, 924.

Madison, L. L., Mebane, D., Unger, R. H., and LochNer, A. (1964). The Hypoglycæmic Action of Ketones II Evidence for a Stimulatory Feedback of Ketones on the Pancreatic Beta Cells. J. clin. Invest., 43 蛋 
Nestel, P. J. (1964). Plasma Triglyceride Concentration and Plasma Free Fatty Acid Changes in Response to Norepinephrine in Man. J. clin. Invest., 43, 77.

Paoletti, R., Smith, R. L., Maickel, R. P., and Brodie, B. B. (1961). Identification and Physiological Role of Norepinephrine in Adipose Tissue. Biochem. Biophys. Res. Commun., 5, 424.

Raben, M. S., Landolt, R., Smith, F. A., Hofmann, K., and Yajima, H. (1961). Adipokinetic Activity of Synthetic Peptides Related to Corticotropin. Nature, (Lond.), 189, 681.

Rabinowitz, D., and ZierLer, K. L. (1962). Forearm Metabolism in Obesity and its response to Intraarterial Insulin. Characterisation of Insulin Resistance and Evidence for Adaptive Hyperinsulinism. $J$. clin. Invest., 41, 2173.

Recant, L., Alp, H., KосH, M. B., and Eggeman, J. (1963). Non-esterified Fatty-acid-releasing Activity in Diabetic Serum. Lancet, 2, 614.

Renold, A. E., and CAHILl, G. F., Jr. (1964) Eds. Handbook on Adipose Tissue. Amer. Phys. Soc., in press.

RizACK, M. A. (1961). An Epinephrine-sensitive Lipolytic Activity in Adipose Tissue. J. biol. Chem., 236, 657.

RizACK, M. D. (1964). Activation of an Epinephrine-sensitive Lipolytic Activity from Adipose Tissue by Adenosine 3',5'-phosphate. J. biol. Chem., 239, 392.

Roth, J., Glick, S. M., Yalow, R. S., and Berson, S. A. (1963). Secretion of Human Growth Hormone: Physiologic and Experimental Modification. Metabolism, 12, 577.

Rudman, D., Brown, S. J., and Malkin, M. F. (1963). Adipokinetic Actions of Adrenocorticotrophin, Thyroid-stimulating Hormone, $\alpha$ - and $\beta$-melanocyte-stimulating Hormones, Fraction $\mathrm{H}$, Adrenaline and Noradrenaline in the Rabbbit, Guinea-pig, Hamster, Rat, Pig and Dog. Endocrinology, 72, 527.

Rudman, D., Malkin, M. F., Brown, S. J., Garcia, L. A., and Abell, L. L. (1964). Inactivation of Adrenocorticotrophin, $\alpha$ - and $\beta$-melanocyte-stimulating Hormones, Vasopressin and Pituitary Fraction $H$ by Adipose Tissue. J. Lipid Res., 5, 38.

Rudman, D., Reid, M., Seidman, F., di Girolamo, M., Wertheim, A. R., and Bern, S. (1961). Purification and Properties of a Component of the Pituitary Gland which Produces Lipæmia in the Rabbit. Endocrinology, 68, 273.

SCHOENHEIMER, R., and RitTENBERG, D. (1937). Deuterium as an Indicator in the Study of Intermediary Metabolism. IX. The Conversion of Stearic Acid into Palmitic Acid in the Organism. J. biol. Chem., $120,155$.

ShAFrIR, E., and Gorin, E. (1963). Release of Glycerol in Conditions of Fat Mobilisation and Deposition. Metabolism, 12, 580.

STEINBERG, D. (1963). Fatty Acid Mobilisation: Mechanism of Regulation and Metabolic Consequences. In "The Control of Lipid Metabolism", p. 111. Ed. J. K. Grant. London and New York: Academic Press. SutHerLand, E. W., Jr. (1962). The Biological Role of Adenosine $3^{\prime}, 5^{\prime}$-phosphate. Harvey Lectures, 57, 17.

Vaughan, M. (1961). The Metabolism of Adipose Tissue in vitro. J. Lipid Res., 2, 293.

VAughan, M., and Steinberg, D. (1963). Effect of Hormones on Lipolysis and Esterification of Free Fatty Acids during Incubation of Adipose Tissue in vitro. Ibid, 4, 193.

WerTHEIMER, E., and SHAFRIR. E. (1960). Influence of Hormones on Adipose Tissue as a Center of Fat Metabolism. Recent Progr. Hormone Res., 16, 467.

Wertheimer, E., and Shapiro, B. (1948). Physiology of Adipose Tissue. Physiol. Rev., 28, 451.

Winegrad, A. I. (1962). Endocrine Effects on Adipose Tissue Metabolism. Vitam and Horm., $20,141$. 